\title{
Time spent by people managing chronic obstructive pulmonary disease indicates biographical disruption
}

This article was published in the following Dove Press journal:

International Journal of COPD

15 January 2014

Number of times this article has been viewed

\section{Tanisha Jowsey \\ Laurann EYen \\ Nasser Bagheri \\ Ian S McRae}

Australian Primary Health Care Research Institute,

Australian National University,

Acton, ACT, Australia
Correspondence: Tanisha Jowsey Australian Primary Health Care Research Institute, Building 63, Australian National University, Acton, ACT 0200, Australia Email tanisha.jowsey@anu.edu.au
Abstract: Since Bury's 1982 proposal that chronic illness creates biographical disruption for those who are living with it, there has been no effort to quantitatively measure such disruption. "Biographical disruption" refers to the substantial and directive influence that chronic illness can have over the course of a person's life. Qualitative research and time use studies have demonstrated that people with chronic illnesses spend considerable amounts of time managing their health, and that these demands may change over time. This study was designed to measure the time that older people with chronic illnesses spend on selected health practices as one indicator of biographical disruption. We look specifically at the time use of people with chronic obstructive pulmonary disease (COPD). As part of a larger time use survey, a recall questionnaire was mailed to 3,100 members of Lung Foundation Australia in 2011. A total of 681 responses were received (22.0\% response rate), 611 of which were from people with COPD. Descriptive analyses were undertaken on the amount of time spent on selected health-related activities including personal care, nonclinical health-related care, and activity relating to health services. Almost all people with COPD report spending some time each day on personal or home-based health-related tasks, with a median time of 15 minutes per day spent on these activities. At the median, people also report spending about 30 minutes per day exercising, 2.2 hours per month (the equivalent of 4.4 minutes per day) on nonclinical health-related activities, and 4.1 hours per month (equivalent to 8.2 minutes per day) on clinical activities. Excluding exercise, the median total time spent on health-related activities was 17.8 hours per month (or 35.6 minutes per day). For people in the top $10 \%$ of time use, the total amount of time was more than 64.6 hours per month (or 2.2 hours per day) excluding exercise, and 104 hours per month (or 3.5 hours per day) including exercise. The amount of time spent on health-related activity, such as engaging in personal care tasks, may be regular and predictable. The execution of these tasks generally takes relatively small amounts of time, and might be incorporated into daily life (biography) without causing significant disruption. Other activities may require large blocks of time, and they may be disruptive in a practical way that almost inevitably disrupts biography. The amount of time required does not appear to alter in relation to the time since diagnosis. The scale of time needed to manage one's health could easily be interpreted as disruptive, and for some people, even overwhelming.

Keywords: chronic illness, chronic obstructive pulmonary disease, disrupted biography, experience, self-management, time use

\section{Introduction}

Bury ${ }^{1}$ proposes that chronic illness is experienced as a disruption to an individual's biography, to their living out the life they imagine. "Chronic illness," writes Bury, "is precisely that kind of experience where the structures of everyday life and the forms of knowledge which underpin them are disrupted." Such disruption, he observes, can be responded to through the mobilization of resources, including the use of time. 
This observation is based on his study, which was conducted in the early 1980s, involving 30 people who had rheumatoid arthritis. Later, in their seminal paper on the home-based management of chronic illness, Corbin and Strauss ${ }^{2}$ said that chronic illness is experienced in terms of work, including the time people spend on "illness work", daily health practices, and "biographical work". "Management of an illness in the home" they write, "is not accomplished without difficulty and a great deal of effort, unless the regimens are relatively simple and do not greatly interfere with the normal flow of life." 2 This difficulty and effort born of chronic illness is created by work and by the amount of time spent incorporating the needs arising from chronic illness into the fabric of daily life. Taking these notions of "biographical disruption" and "work" as a platform, our study seeks to explore whether the amount of time spent on illness work and daily health practices might cause biographical disruption, and whether such disruptions increase or decrease over time. In doing so, we take the case of people with chronic obstructive pulmonary disease (COPD). Drawing on the findings from a time use survey we conducted in Australia in 2011, ${ }^{3}$ we have established that people with arthritis spend approximately 7.8 hours (median) per month on health practices. We also identified that people with COPD spent more time overall on health practices than those with arthritis or other chronic illnesses. ${ }^{3}$ Returning to Bury's study, ${ }^{1}$ and combining his findings with our own, if people with arthritis spend about 7.8 hours each month on health practices, and they experience this time as contributing to a sense of disruption, then people with COPD - an illness associated with a higher magnitude of time use - may experience the same, or even a greater sense, of disruption.

This paper details the "work" of COPD in terms of the amount of time that people with COPD spend on particular health practices, which may be driven by COPD or other conditions, and which informs our understanding of the reality faced by COPD patients. We assess to what extent that time use is informed by how much time has passed since the patients were diagnosed with COPD. Doing so allows for a direct comparison to be made with the time demands faced by people with arthritis, as reported in Bury's study, ${ }^{1}$ although the explicit impact of these time demands cannot be assessed in the context of a time use survey.

In addition to the theoretical driver, biographical disruption, behind this article, the impact of COPD time use information can be seen in public health and service terms. Not only is COPD associated with high time use, but it is also a major cause of morbidity and mortality worldwide. ${ }^{4}$ Acute exacerbations of COPD are common; they often require hospitalization and are associated with high mortality rates. ${ }^{5}$ Research shows mortality rates as high as $23 \%$ after 1 year from COPD-related hospitalization. ${ }^{5}$ In Australia, COPD remains a leading underlying cause of death and disability. The average length of stay in hospital due to COPD exacerbation in 2007-2008 was 6.9 days, which was double the average amount of time spent in hospital due to other illnesses or other reasons (3.3 days). ${ }^{6}$ While some aspects of the health system and personal costs of COPD in relation to the use of health services are known, ${ }^{7,8}$ very little is known about management of COPD outside of hospital settings.

Qualitative studies have shown that COPD contributes to patient and carer burden, it informs their help-seeking behaviors, and can come at considerable personal cost. ${ }^{7,9-11}$ It is within such literature that the kinds of "work" that Corbin and Strauss have outlined can be identified. ${ }^{12}$

Gysels and Higginson ${ }^{13}$ note that people's experiences of time can be disrupted by COPD, as evidenced by their narratives, which lack reference to any future orientations. Pinnock et $\mathrm{al}^{14}$ have also identified the role of time in COPD experiences, suggesting that the illness becomes "a way of life" (that is, over time), which contributes to difficulties in identifying when support, including palliative support, is needed. However, despite the ubiquitous influential nature of time on experience, qualitative studies concerning COPD experience seldom account for time use beyond the observations that some tasks take longer to complete due to breathlessness and reduced mobility.

Many people with COPD have a range of comorbid conditions, and these conditions will also make demands on their time, so time use by people with COPD is not necessarily the same as the time demands directly associated with COPD per se. However, the health related time demands of the community of people with COPD, regardless of other co-morbidities, are material and measurable.

The nature of the health-related activities undertaken by people with COPD and the time required to do them has not been examined. Specific practices of self-management and the amount of time spent in rehabilitation programs may require considerable time commitments from the patient. Further, as the disease progresses, the time spent by people with COPD on health practices ("work") may change dramatically in terms of the activities undertaken and the quantity of time required.

A recent literature review by Jowsey et al $^{15}$ concerning patient and informal carer time use did not identify any studies reporting how much time people with COPD spend managing their health. However, it did identify several time use studies that have provided limited information concerning specific 
populations' time use in terms of time spent on health-related activities. ${ }^{16,17}$ It also identified literature reporting on the recommended time use of people with diabetes. ${ }^{18,19}$ Russell et $\mathrm{l}^{18}$ report that diabetes educators estimate that people with diabetes should spend, on average, 2 hours each day undertaking tasks that are specific to diabetes management.

We undertook a national time use survey of older adults to establish the amount of time they spent on health work, and found that people with COPD reported spending the highest amount of time on health-related activities. ${ }^{3,20}$ Here, we analyze which of a selected group of tasks people spend most of their time on, and suggest that the total amount of time spent on health practices may indeed contribute to a person's sense that his or her daily biography (and indeed, their life course) has been disrupted by chronic illness.

\section{Methods}

The data collection and analysis methods have been described in full elsewhere. ${ }^{3}$ Recruitment was undertaken through three national organizations, Lung Foundation Australia (LFA), National Seniors Australia (NSA), and the National Diabetes Services Scheme (NDSS). This article reports only findings from the LFA sample.

\section{Sample}

Participants were selected from members of LFA (a national nonprofit, advocacy, education, fundraising, and support organization with over 14,000 members). All those members aged $>50$ years and recorded by LFA as joining due to COPD were included in the study (a total of 3,062 people) although, as we see later, not all of these people have reported a diagnosis of COPD.

Data were collected on standard demographic variables, the respondents' perceptions of their own health (using the Short Form-12 and the EuroQoL - both standard measures of self-assessed health) and the chronic illnesses with which they had been diagnosed. A series of questions related to health services use - including the type and number of health professionals consulted in the previous 3 months and attendance at emergency departments in the last 12 months - were investigated. Three multipart questions were designed to obtain information about time use on personal home-based activities, nonclinical, and clinical activities (see Table 1). Respondents who were also carers were asked additionally about the same activities from the perspective of their caring role.

The questionnaire was piloted with 28 people from an earlier survey who had indicated an interest in being
Table I Time questions

\begin{tabular}{|c|c|c|c|}
\hline $\begin{array}{l}\text { Activity } \\
\text { type }\end{array}$ & Task & Hours & Minutes \\
\hline $\begin{array}{l}\text { Home } \\
\text { activities }\end{array}$ & $\begin{array}{l}\text { On most days, how much time do } \\
\text { you generally spend on each of the } \\
\text { following? } \\
\text { - Sorting your medications } \\
\text { - Preparing your medications } \\
\text { - Taking your medications } \\
\text { - Carrying out treatments } \\
\text { - Testing or monitoring your health } \\
\text { - Preparing special foods } \\
\text { - Taking exercise/stretching }\end{array}$ & & \\
\hline $\begin{array}{l}\text { Nonclinical } \\
\text { activities }\end{array}$ & $\begin{array}{l}\text { In the last month how much time did } \\
\text { you spend on each of the following? } \\
\text { - Shopping for medicines, } \\
\text { equipment or disposables, other } \\
\text { necessary health items for yourself } \\
\text { - Shopping for special foods you } \\
\text { may need for yourself } \\
\text { - Attending rehabilitation programs } \\
\text { - Attending health education } \\
\text { of self-management programs } \\
\text { - Attending support groups such as } \\
\text { cancer or diabetes groups } \\
\text { - Looking for and reading health } \\
\text { information }\end{array}$ & & \\
\hline $\begin{array}{l}\text { Clinical } \\
\text { activities }\end{array}$ & $\begin{array}{l}\text { In the last month how much time did } \\
\text { you spend on each of the following? } \\
\text { - Organizing appointments for } \\
\text { yourself } \\
\text { - Organizing travel to and from } \\
\text { health-related appointments } \\
\text { - Travelling to and from health- } \\
\text { related appointments, including } \\
\text { support groups } \\
\text { - Sitting in waiting rooms } \\
\text { With the doctor or other health } \\
\text { professional for consultation, } \\
\text { advice, or treatment } \\
\text { - Having blood tests, X-rays, or } \\
\text { other tests } \\
\text { - Having other medical treatments } \\
\text { (for example, dialysis, } \\
\text { chemotherapy, radiotherapy) }\end{array}$ & & \\
\hline
\end{tabular}

involved in further research, and following their feedback, the questionnaire was modified and retested with a group of members of a local health service consumer network. The final survey was mailed to selected individuals with the option to complete it on line using SurveyMonkey ${ }^{\circledR}$ (Palo Alto, CA, USA), a proprietary survey tool, or to complete the form and return it by prepaid post.

\section{Data collection and analysis}

Data were entered into SPSS files for analysis. Online responses were merged electronically. Analysis was undertaken using 
IBM SPSS Statistics for Windows, Version 19.0 (IBM Corporation, Armonk, NY, USA) and Stata 11 (StataCorp LP, College Station, TX, USA). Confidence intervals were derived using bootstrapping techniques within Stata 11.

Descriptive analysis was used to explore the components of time use and the relationship between self-assessed health, the numbers of medications taken, the amount of time since diagnosis, and other selected time components.

\section{Time measurement}

We asked how much time was spent "on most days" for frequent, regular activities, such as managing and taking medication, and "in the last month" for less regular activities, such as shopping for special food, attending support groups, or visiting a doctor. The times reported have been trimmed to remove impossible and implausible values for each component question and for aggregates. Times reported were converted by dividing monthly figures by 30 to give daily time use, or multiplying daily time use by 30 for a monthly figure.

The time distributions are highly skewed, being truncated at zero, but they frequently have a small number of very large values, so medians are used rather than means. Since one of the major questions is which groups face the greatest time demands, the 90th percentiles are also discussed to show the time demands experienced by the top $10 \%$ of respondents.

The last component of the daily activities relates to engaging in exercise and stretching. Exercise time is discussed separately, and has been excluded from most totals as exercise times were variable, and we were unable to identify whether the respondent was exercising for recreation, or for a specific health reason.

While almost all respondents reported spending time on many health-related activities, few reported spending time on all of them. Therefore, the estimates of the amount of total time included all observations (including the relatively small numbers of zeros), but for the amount of time spent on individual activities, we reported on both the proportion of respondents undertaking these tasks and the amount of time spent by those undertaking them.

\section{Ethics}

Study approval was obtained from the Australian National University Human Research Ethics Committee (Protocol number: 2010/468).

\section{Results}

Six hundred and eighty-one people returned completed surveys (a response rate of $22.2 \%$ ). Six hundred and eleven reported having had a formal diagnosis of COPD; the other seventy were probably family members who joined LFA as COPD members, but did not have COPD themselves. The analysis that follows is based on only those individuals with COPD ( $\mathrm{N}=611)$. As indicated in Table 1, the survey categorized time use questions into those concerning home activities, clinical activities, or nonclinical activities.

The total time spent on health-related activity by people with COPD (median times: 17.8 hours per month excluding exercise or 31.7 hours per month including exercise) is three times greater than the amount of time spent by older adults in the general population, in each of the three categories of activity (which we have reported previously). ${ }^{3}$ As indicated in Table 2, most respondents spent time sorting medications (66.4\%), preparing medications (53.1\%), and/or taking medications $(90.1 \%)$. The median time reported as being spent on each of these three activities was 5 minutes daily.

Most respondents (69.5\%) spent time exercising or stretching; the median time spent on exercising or stretching was 15 hours per month or 30 minutes daily. Only $9.0 \%$ of respondents engaged in the preparation of special foods, but for those who did this, the activity was associated with high time use (median time spent was 15 hours per month or thirty minutes daily). While there was little difference in the proportion of males and females shopping for or preparing special foods, females spent around twice as much time preparing these foods as males (Table S1). Most respondents (96.7\%) spent time on at least one daily home activity, and the median time spent on all home activities was 45 minutes per day or 22.5 hours per month (including time spent on exercise). Excluding the amount of time spent on exercise, the total time spent (by $95.6 \%$ of respondents) on home activities was considerably less, with a median of 7.5 hours per month or 15 minutes per day.

Two other activities were identified as having relatively high time use by those who engaged in the activities. The median amount of time spent carrying out treatments was 5.0 hours per month (undertaken by $24.6 \%$ of respondents) and the time spent attending rehabilitation programs was 4.0 hours per month (undertaken by $19.6 \%$ of respondents).

Fewer respondents spent time on clinical activities $(88.6 \%)$ than on home activities, and overall, the clinical activities required less time (median of 4.1 hours per month by those engaging in clinical activities). Overall $78.3 \%$ of respondents reported spending any time waiting in waiting rooms, and the median time reported was 1 hour per month. Most respondents spent time in consultations or having 
Table 2 Time on particular activities

\begin{tabular}{|c|c|c|c|}
\hline Activity & $\begin{array}{l}\text { Proportion } \\
\text { undertaking this } \\
\text { activity }(\mathrm{N}=6 \mathrm{I} \mathrm{I}) \\
\% \text { Active }\end{array}$ & $\begin{array}{l}\text { Median time } \\
\text { if undertaking } \\
\text { this activity } \\
\text { Median } \\
(95 \% \mathrm{Cl})\end{array}$ & $\begin{array}{l}\text { 90th percentile of } \\
\text { time if undertaking } \\
\text { this activity } \\
90 \text { th percentile } \\
(95 \% \mathrm{Cl})\end{array}$ \\
\hline \multicolumn{4}{|l|}{ Home activities (minutes per day) } \\
\hline Sorting your medication? & 66.4 & $5(4.0-6.0)$ & $20(11.5-28.5)$ \\
\hline Preparing your medication? & 53.1 & $5(5-5)$ & $15(12.6-17.4)$ \\
\hline Taking your medication? & 90.1 & $5(5-5)$ & $20(10.2-29.8)$ \\
\hline Carrying out treatments? & 24.6 & $10(5.2-14.9)$ & $120(83.7-156.3)$ \\
\hline Testing or monitoring your health? & 22.1 & $5(2.3-7.7)$ & $30(14.6-45.4)$ \\
\hline Preparing special foods? & 9.0 & $30(19.5-40.5)$ & $120(13.5-226.5)$ \\
\hline Exercising/stretching? & 69.5 & $30(30-30)$ & $90(63.5-116.5)$ \\
\hline Total home activities (minutes per day) excluding exercise & 95.6 & $15(\mid 1.8-18.2)$ & $78(63.5-92.5)$ \\
\hline Total home activities (minutes per day) including exercise & 96.7 & $45(4 \mid .3-48.7)$ & $150(125.0-175.0)$ \\
\hline \multicolumn{4}{|l|}{ Nonclinical activities (hours per month) } \\
\hline $\begin{array}{l}\text { Shopping for medicine, equipment or disposables, } \\
\text { other necessary health items for yourself? }\end{array}$ & 71.5 & $0.5(0.5-0.5)$ & $2(1.3-2.7)$ \\
\hline Shopping for special foods you may need for yourself? & 17.9 & $\mathrm{I}(0.7-1.3)$ & $6(2.6-9.4)$ \\
\hline Attending rehabilitation programs? & 19.6 & $4(3.7-4.3)$ & $16(10.3-21.7)$ \\
\hline Attending health education or self-management programs? & 13.9 & $3(1.9-4.1)$ & $16(6.9-25.1)$ \\
\hline Attending support groups, such as cancer or diabetes groups? & 14.4 & $2(1.6-2.4)$ & $12(2.8-2 \mid .2)$ \\
\hline Looking for and reading health information? & 42.7 & I $(0.9-||)$. & $5(3.7-6.3)$ \\
\hline Total nonclinical activities (hours per month) & 85.0 & $2.2(1.8-2.5)$ & $16(12.8-19.2)$ \\
\hline \multicolumn{4}{|l|}{ Clinical activities (hours per month) } \\
\hline Organizing appointments for yourself? & 62.3 & $0.3(0.3-0.3)$ & $I(I-I)$ \\
\hline Organizing travel to and from health-related appointments? & 30.8 & $0.5(0.45-0.55)$ & $2.5(1.3-3.7)$ \\
\hline $\begin{array}{l}\text { Travelling to and from health-related appointments, } \\
\text { including support groups? }\end{array}$ & 67.1 & $1.5(0.9-2.1)$ & $8(5.3-10.7)$ \\
\hline Sitting in waiting rooms? & 78.3 & $I(I-I)$ & $4(3.6-4.4)$ \\
\hline $\begin{array}{l}\text { With the doctor or health professional for consultation, } \\
\text { advice or treatment? }\end{array}$ & 73.9 & $0.8(0.6-1.1)$ & $3.5(2.1-4.9)$ \\
\hline Having blood tests, $X$-rays, or other tests? & 55.2 & $0.7(0.4-1.0)$ & $3(2.3-3.7)$ \\
\hline Having other medical treatments? & 5.1 & I $(0-2)$ & $16(10.5-21.5)$ \\
\hline Total health services-related activities (hours per month) & 88.6 & $4.1(3.4-4.8)$ & $18(15.3-20.7)$ \\
\hline Total activities (hours per month) excluding exercise & 98.1 & $17.8(15.4-20.3)$ & $64.6(53.6-75.7)$ \\
\hline Total activities (hours per month) including exercise & 98.6 & $31.7(28.9-34.4)$ & $104(92.4-115.6)$ \\
\hline
\end{tabular}

Abbreviations: $\mathrm{N}$, number; $\mathrm{Cl}$, confidence interval.

treatments $(73.9 .0 \%)$, travelling to and from health appointments $(67.1 \%)$, and/or organizing appointments $(62.3 \%)$. The median time spent on each of these activities was 0.8 hours, 1.5 hours, and 0.3 hours per month, respectively.

As shown in Table 3, many respondents took multiple prescribed medications in order to help manage their health. These medications could have been prescribed to manage COPD, as well as other chronic illnesses. As would be expected, greater numbers of medications were associated with increased amounts of time spent sorting, preparing, and taking medications. Ten percent of respondents, however, recorded that although they took medications, this activity required no time at all. It is possible that these respondents did not understand the survey question, or they did not answer the question because they considered the quantity of time required for such tasks to be inconsequential. Indeed, for many respondents, the median times spent on these tasks appear to be relatively small, with between 2 minutes and 10 minutes required for each task, depending on the number of medications taken. However, for those respondents in the 90th percentiles, the median times are between three and four times higher. The top 5\% of respondents spend 1 hour or more on these three tasks, and the top 10\% spent 45 minutes or more.

\section{Self-rated health and time spent}

Time spent on each activity group generally increased as self-rated health declined, although the small number of respondents reporting excellent health meant that the estimates for this group had very wide confidence intervals, 
Table 3 Number of medications and time taken for each medication activity

\begin{tabular}{|c|c|c|c|c|}
\hline \multirow{4}{*}{$\frac{\text { Activity }}{\text { Number of medications }}$} & \multirow[t]{4}{*}{$\mathbf{N}$} & \multirow{4}{*}{$\begin{array}{l}\text { Proportion undertaking } \\
\text { this activity } \\
\% \text { Active (reporting time) }\end{array}$} & \multicolumn{2}{|l|}{ Minutes per day } \\
\hline & & & \multirow{3}{*}{$\begin{array}{l}\text { Median time if } \\
\text { undertaking this activity } \\
\text { Median }(95 \% \mathrm{Cl})\end{array}$} & \multirow{3}{*}{$\begin{array}{l}\text { 90th percentile of time } i \\
\text { undertaking this activity } \\
\text { 90th percentile }(95 \% \mathrm{Cl})\end{array}$} \\
\hline & & & & \\
\hline & & & & \\
\hline \multicolumn{5}{|c|}{ Activity: sorting your medication? } \\
\hline I-2 medications & 53 & 34.0 & $2(0.0-4.5)$ & $5(0.0-13.5)$ \\
\hline 3-5 medications & 206 & 63.8 & $5(5-5)$ & $15(9.9-20.1)$ \\
\hline $6-10$ medications & 262 & 73.5 & $5(0.3-9.7)$ & $20(10.5-29.5)$ \\
\hline$>10$ medications & 78 & 77.1 & $10(6.5-13.4)$ & $30(14.1-45.9)$ \\
\hline Total & 611 & 66.4 & $5(5-5)$ & $20(11.5-28.5)$ \\
\hline \multicolumn{5}{|c|}{ Activity: preparing your medication? } \\
\hline I-2 medications & 53 & 35.3 & $\mathrm{I}(0.3-\mathrm{I.7})$ & $5(0-\mid 4.2)$ \\
\hline $3-5$ medications & 206 & 45.5 & $5(4.3-5.7)$ & $10(8.0-11.0)$ \\
\hline 6-10 medications & 262 & 63.4 & $5(5-5)$ & $15(12.4-17.6)$ \\
\hline$>10$ medications & 78 & 55.5 & $10(5.5-14.5)$ & $30(17.4-42.6)$ \\
\hline Total & 611 & 53.1 & $5(5-5)$ & $15(12.0-17.6)$ \\
\hline \multicolumn{5}{|c|}{ Activity: taking your medication? } \\
\hline I-2 medications & 53 & 81.4 & $2(0.2-3.8)$ & $10(1.9-18.1)$ \\
\hline 3-5 medications & 206 & 89.9 & $5(4.8-5.2)$ & $20(9.9-30.1)$ \\
\hline 6-10 medications & 262 & 93.8 & $5(5-5)$ & $20(9.9-30.1)$ \\
\hline$>10$ medications & 78 & 90.3 & $5(1.0-9.0)$ & $30(17.6-42.4)$ \\
\hline Total & 611 & 90.1 & $5(5-5)$ & $20(10.1-29.9)$ \\
\hline
\end{tabular}

Abbreviations: $\mathrm{N}$, number; $\mathrm{Cl}$, confidence interval.

and while the patterns were stable, few of the differences were significant. The tables outlining this result are shown in the supplementary file (Tables S2-S5).

The differences between those in good health and those in poor health were highly significant for the amount of time taken for home activities (particularly if exercise was not included) and health service-related activities. There were no significant differences between levels of self-reported health in the amount of time spent on nonclinical activities.

\section{Does having a partner matter?}

One factor that was seen as likely to impact the time spent on health care was whether a patient had a partner. Comparing those with a partner to those with no partner, but who had been married, shows that those with partners spent more time on their health than those without partners, with the difference at the median being statistically significant.

\section{Does the quantity of chronic} illness work change over time?

The survey asked respondents how old they were when they were first told of their diagnosis of COPD. Of the 611 people with COPD who returned completed surveys, only 537 provided this information: 194 people had been diagnosed with COPD for 5 years or less; 148 people had been diagnosed between 6 years and 10 years; and 195 people had been diagnosed for more than 10 years. For the majority of the activities for which time use was measured, there was little relationship between time use and time since diagnosis.

One exception to this finding was the amount of time spent carrying out treatments where the patterns were suggestive of more time being spent by those who were diagnosed less recently (more than 5 years previously), although none of the differences are significant. There is also a weak indication that there are more people spending very large amounts of time preparing special foods among the more recently diagnosed (those diagnosed within 5 years or less). There is a weak suggestion that those who had been diagnosed the longest may spend longer preparing and taking medications which, if true, may relate to age and the number of medications taken. Other suggestive patterns include a decline in time spent on shopping for special foods among those diagnosed long ago, and a similar pattern was indicated for the amount of time spent attending rehabilitation clinics. A larger sample may allow for significance to be reached in some of these patterns.

\section{Discussion}

People with COPD among their conditions spend more time on managing their health than people with arthritis, whom Bury found encountered biographical disruption. ${ }^{1}$ 
As previously mentioned, our survey is not exhaustive, and is likely to under-represent the amount of time and disruptive elements associated with hospitalizations. It also has not captured those temporal elements of chronic illness experiences that are spent planning or worrying about illness, nor did the survey capture which activities were foregone due to spending time on health-related activities, and the impact of that on the individual's lived experience.

The findings suggest that some people with COPD spend considerable amounts of time managing their health, both in clinical and nonclinical settings - much of which is likely to be spent managing their COPD, but some of which will be related to other comorbid conditions. Some activities require daily commitments, such as managing and taking prescribed medication, and undertaking exercise to maintain or improve health. Other activities require larger amounts of time less frequently. The median amount of time required to manage tasks (excluding exercise) amounts to 17.8 hours per month (equivalent to 35.6 minutes daily), and for those in the top $10 \%$, the total amount of time spent was at least 64.6 hours per month (more than 2 hours daily).

The less-than-daily clinical and nonclinical activities are likely to be experienced in a different "rhythm" than everyday activities. Rather, a task may occur just once a month and instead of taking 30 minutes, it may take 2 hours. This oscillation between smaller rhythmic activities and larger time-intensive, sporadic activities informs the individual's perception of the "work" associated with managing chronic illness. Activities that occur frequently, but for shorter durations, actually amount to a greater quantity of time over 1 month than do the less frequent, but time-intensive activities. However, it is often these latter activities that cause the greatest sense of disruption to daily life, as it is more difficult to habituate these tasks into familiar routines and rhythms.

In our study, fewer respondents reported spending time on clinical activities (88.6\%) than on home activities (96.7\%), and overall, the clinical activities required less time (median of 4 hours per month by those engaging in clinical activities). However, our survey was sent to people in the community, and it did not examine the amount of time spent as a patient in hospital - a common and time-consuming occurrence for many people with COPD. ${ }^{5}$ The findings reported here represent only a specific portion of time spent on health-related activities, and thereby under-represent the possible disruption that chronic illness can cause.

The findings also indicate that the amount of time people spend on health work is associated with sex. While a similar number of females and males prepared special foods each day, females spent significantly more time on this task than males. Stronger associations were evident with self-reported health status than sex for the amount of time spent on home and clinical activities.

People with partners spend significantly more time on their health care than those without partners (although the differences are not large), possibly suggesting that those with partners are able to share more day-to-day work, and thus have more time to address their health care needs.

We were surprised to find that the amount of time that had passed since a person was diagnosed with COPD did not strongly impact their time spent on health work. We had suspected that time requirements would be significantly greater either at the time immediately leading up to and following diagnosis, or for people who had been diagnosed for many years and whose speed in carrying out tasks could be slowed. However, such patterns were not strong. Alternatively, it is possible that as people's illnesses progress, their capacity to undertake certain health-related activities decreases to a point where they require others - such as informal carers - to take over the management of such tasks. If this is the case, we could expect to see less time spent on tasks by people with COPD over time.

Returning to Bury ${ }^{1}$ and to Corbin and Strauss, ${ }^{2}$ the question remains as to whether COPD is a cause of biographical disruption and work. After consideration of the findings, we suggest that the amount of time spent by people with COPD on home, clinical, and nonclinical activities is substantial, and that time spent on these tasks constitutes work. The overall quantity of time spent, the diversity of tasks undertaken, the timing and rhythms associated with each task, and the different amounts of time required for each task, all contribute to the extent to which chronic illness is experienced as disruptive in daily life, and to the individual's overall biography. The disruption to biography is keenly felt through one's sense that time spent on health-related activities robs the individual of time they could otherwise spend on other valued activities in other aspects of their lives. This article has provided information on several of these factors and in doing so, we suggest, contributes to quantifying the ways in which chronic illness contributes to biographical disruptions and a reshaping of biography. The future biography of an individual with COPD entails the moments shaped by illness, which are identifiable in terms of time spent on its management.

We have previously noted that "Health policies in most Western systems encourage patients and their carers to use self-management approaches to remain as healthy as 
possible, and so to live independently for longer and avoid unnecessary hospital admissions." ${ }^{3}$ Self-management though, as the findings here indicate, can come at considerable time costs to people with chronic illness. Even if engaging in self-management activities does enable people to remain as healthy as possible, live independently, and avoid unnecessary hospitalizations, it can still be experienced as an ongoing disruption to daily life and to biography as a whole.

\section{Strengths and limitations of the study}

This is the first study that attempts to measure the amount of time spent by people with COPD on health-related activities, and it provides a base for further research in the field. It is also the first to draw conclusions about the theories posed by Bury ${ }^{1}$ and Corbin and Strauss' ${ }^{2}$ investigations of selfreported time use data.

We have previously noted the limitations of the survey method. ${ }^{3}$ The use of recall estimates rather than diaries is associated with recall bias. ${ }^{21}$ However, one of the key strengths of recall estimates is that they do provide a snapshot of time use, which minimizes the burden on participants, and which can (as in this study) cover a longer period of time than diaries can usually address, thereby giving much more meaningful distributions of time use over longer periods.

The sample was drawn from a single member organization whose purpose is to promote knowledge about the illness and to support its members. Likewise, the response rate of $22 \%$ may cause biases. Those who chose to respond may be more motivated, and/or may be in better health than those who did not, although basic testing of age, sex, and region responses showed reasonable representation of the LFA population. While we have made attempts to capture diverse aspects of COPD management, we have not attempted to identify all health-related activities. That being the case, it is likely that the time estimates provided here under-represent the true time costs associated with COPD.

In particular, we have not measured the amount of time people with COPD spend on activities of daily living (ADL), such as running errands or getting dressed or, as stated previously, time spent as an inpatient in hospital. ADL are likely to take longer to complete, or they may be beyond the individual's capability due to the nature of COPD. ${ }^{22,23}$ The amount of time spent on ADL may further indicate biographical disruption.

The application of time use data to sociological theory has some limits. In this case, the data do not provide information on how the time spent on tasks was experienced. While we have suggested that substantive quantities of time spent on managing health could create disruptions to daily life and to overall biography, such findings would be strengthened by qualitative research that explored the way this time was experienced and how it shaped people's ideas about their biographies.

\section{Conclusion}

People with COPD report spending a median of 15 minutes each day on personal or home-based tasks. At the median, those who exercise report spending about 30 minutes per day exercising, 2.2 hours per month (or 4.4 minutes per day) on other nonclinical activities, and 4.1 hours per month (equivalent to 8.2 minutes per day) on clinical activities. For people reporting times in the top $10 \%$ of time use, the total time excluding exercise amounts to 64.6 hours per month, which is equivalent to 2 hours and 9 minutes daily. The amount of time spent on health-related activities, such as personal care tasks, may be regular and predictable. The execution of these tasks generally takes relatively small amounts of time, and might be incorporated into one's biography without causing significant disruption. However, these are the tasks that are done every day of the year and must, of necessity, substitute for other activities. Other activities may require large blocks of time, and they are so clearly practically disruptive that they will almost inevitably be biographically disruptive. The time required does not appear to alter in relation to the time since diagnosis.

We conclude that the amount of time spent on tasks associated with managing one's health constitutes a significant part of what Corbin and Strauss call the "work" of chronic illness. This study identifies that those with the highest levels of time spent on a selection of health-related activities (or "work") spend an average of more than 3 hours a day on these tasks alone. These time use findings suggest the likelihood that COPD is experienced as disruptive to the individual's daily rhythms and to his or her overall biography.

\section{Acknowledgments}

This research was undertaken as part of The Serious and Continuing Illnesses Policy and Practice Study (SCIPPS), a National Health and Medical Research Council-funded program (no: 402793) conducted at The Australian National University and the University of Sydney, and administered by the Menzies Centre for Health Policy.

The authors would like to thank Lung Foundation Australia for their assistance in carrying out this study. In particular, we thank the members of this organization who completed the survey. We also thank our colleagues in 
the Serious and Continuing Illnesses Policy and Practice Study for their contributions. Ms Jowsey is undertaking postdoctoral research at the Australian National University, and this article forms part of her thesis.

\section{Author contributions}

LEY, TJ, and ISM contributed to the conception of the study and the development of the tool. LEY and ISM managed the survey process. TJ, ISM, and NB carried out the statistical analyses. TJ carried out the theoretical and data analysis, and led the development of the manuscript. TJ wrote the first draft of the manuscript and managed the revision process. LEY, NB, and ISM provided critical comment on the manuscript. LEY and ISM contributed to the revisions of the manuscript. All authors have been involved in critical revision.

\section{Disclosure}

The authors report no conflicts of interest in this work.

\section{References}

1. Bury M. Chronic illness as biographical disruption. Sociol Health Illn. 1982;4(2):167-182.

2. Corbin J, Strauss A. Managing chronic illness: three lines of work. Qual Sociol. 1985;8(3):224-247.

3. Yen L, McRae IS, Jowsey T, et al. Health work by older people with chronic illness: how much time does it take? Chronic Illn. 2013;9(4): 268-282.

4. World Health Organization [webpage on the Internet]. Burden of COPD. Geneva, Switzerland: World Health Organization; 2013 [cited January 14, 2013]. Available from: http://www.who.int/respiratory/copd/burden/en/ index.html. Accessed. January 14, 2013.

5. Groenewegen KH, Schols AM, Wouters EF. Mortality and mortalityrelated factors after hospitalization for acute exacerbation of COPD. Chest. 2003;124(2):459-467.

6. Dunt D, Doyle C. Signs of progress in the Australian post-2000 COPD experience, but some old problems remain. Int J Chron Obstruct Pulmon Dis. 2012;7:357-366.

7. Gysels M, Higginson IJ. Access to services for patients with chronic obstructive pulmonary disease: the invisibility of breathlessness. J Pain Symptom Manage. 2008;36(5):451-460.
8. Kirby SE, Dennis SM, Jayasinghe UW, Harris MF. Patient related factors in frequent readmissions: the influence of condition, access to services and patient choice. BMC Health Serv Res. 2010;10:216.

9. Gysels MH, Higginson IJ. Caring for a person in advanced illness and suffering from breathlessness at home: threats and resources. Palliat Support Care. 2009; 7(2):153-162.

10. Corcoran KJ, Jowsey T, Leeder SR. One size does not fit all: the different experiences of those with chronic heart failure, type 2 diabetes and chronic obstructive pulmonary disease. Austr Health Rev. 2013;37(1): $19-25$.

11. Habraken JM, Pols J, Bindels PJ, Willems DL. The silence of patients with end-stage COPD: a qualitative study. $B r J$ Gen Pract. 2008;58(557):844-849.

12. Corbin JM, Strauss A. Unending Work and Care: Managing Chronic Illness at Home. San Francisco, CA: Jossey-Bass Publishers; 1988.

13. Gysels M, Higginson IJ. The experience of breathlessness: the social course of chronic obstructive pulmonary disease. J Pain Symptom Manage. 2010;39(3):555-563.

14. Pinnock H, Kendall M, Murray SA, et al. Living and dying with severe chronic obstructive pulmonary disease: multi-perspective longitudinal qualitative study. BMJ. 2011;342:d142.

15. Jowsey T, Yen L, Matthews PW. Time spent on health related activities associated with chronic illness: a scoping literature review. BMC Public Health. 2012;12:1044.

16. Russell LB, Ibuka Y, Abraham KG. Health-related activities in the American Time Use Survey. Med Care. 2007;45(7):680-685.

17. Russell LB, Ibuka Y, Carr D. How much time do patients spend on outpatient visits?: the American time use survey. Patient. 2008;1(3): 211-222.

18. Russell LB, Suh DC, Safford MA. Time requirements for diabetes selfmanagement: too much for many? J Fam Pract. 2005;54(1):52-56.

19. Safford MM, Russell L, Suh DC, Roman S, Pogach L. How much time do patients with diabetes spend on self-care? J Am Board Fam Pract. 2005;18(4):262-270.

20. Jowsey T, McRae IS, Valderas JM, et al. Time's up. Descriptive epidemiology of multi-morbidity and time spent on health related activity by older Australians: a time use survey. PLoS One. 2013;8(4):e59379.

21. Dumont S, Jacobs P, Turcotte V, Anderson D, Harel F. Measurement challenges of informal caregiving: a novel measurement method applied to a cohort of palliative care patients. Soc Sci Med. 2010;71(10): $1890-1895$.

22. Garrod R, Bestall JC, Paul EA, Wedzicha JA, Jones PW. Development and validation of a standardized measure of activity of daily living in patients with severe COPD: the London Chest Activity of Daily Living scale (LCADL). Respir Med. 2000;94(6):589-596.

23. McSweeny AJ, Grant I, Heaton RK, Adams KM, Timms RM. Life quality of patients with chronic obstructive pulmonary disease. Arch Intern Med. 1982;142(3):473-478. 


\section{Supplementary materials}

Table SI Shopping and preparing special foods

\begin{tabular}{|c|c|c|c|c|}
\hline \multirow[t]{2}{*}{ Sex } & \multirow[t]{2}{*}{$\mathbf{N}$} & $\begin{array}{l}\text { Proportion undertaking } \\
\text { this activity }\end{array}$ & \multirow{2}{*}{$\begin{array}{l}\text { Median time if } \\
\text { undertaking this activity } \\
\text { Median }(95 \% \mathrm{Cl})\end{array}$} & \multirow{2}{*}{$\begin{array}{l}\text { 90th percentile of time } \\
\text { if undertaking this activity } \\
\text { 90th percentile }(95 \% \mathrm{CI})\end{array}$} \\
\hline & & $\%$ Active & & \\
\hline \multicolumn{5}{|c|}{ Preparing special foods (minute/day) } \\
\hline Male & 285 & 8.3 & $20(9.9-30.1)$ & $60(0.0-209.5)$ \\
\hline Female & 319 & 9.8 & $60(31.1-88.9)$ & $120(9.3-230.7)$ \\
\hline Total & 611 & 9.0 & $30(19.5-40.5)$ & $120(\mid 3.5-226.5)$ \\
\hline \multicolumn{5}{|c|}{ Shopping for special foods (hours/month) } \\
\hline Male & 285 & 18.5 & $0.6(0.2-1.1)$ & $3(1.5-4.5)$ \\
\hline Female & 319 & 17.0 & I (0.I-I.9) & $8(5.1-11.4)$ \\
\hline Total & 611 & 17.9 & I (0.7-I.3) & $6(2.6-9.4)$ \\
\hline
\end{tabular}

Note: Time spent by people managing chronic obstructive pulmonary disease indicates biographical disruption.

Abbreviations: $\mathrm{N}$, number; $\mathrm{Cl}$, confidence interval.

Table S2 Time spent on home activities including exercise and self-reported health

\begin{tabular}{|c|c|c|c|c|}
\hline \multirow[t]{3}{*}{ Self-reported health } & \multirow[t]{3}{*}{$\mathbf{N}$} & \multirow{3}{*}{$\begin{array}{l}\text { Percent with home activities } \\
\text { time greater than zero } \\
\%\end{array}$} & \multicolumn{2}{|c|}{$\begin{array}{l}\text { Home activities including exercise } \\
\text { (minutes per day) }\end{array}$} \\
\hline & & & \multicolumn{2}{|c|}{ Median and percentile including zero values } \\
\hline & & & Median $(95 \% \mathrm{CI})$ & 90th percentile $(95 \% \mathrm{Cl})$ \\
\hline Excellent/very good & 30 & 100 & $50(35.6-64.4)$ & $94(0.0-386.3)$ \\
\hline Good & 115 & 94.7 & $39(31.1-46.8)$ & $125(88.9-161.0)$ \\
\hline Poor/fair & 464 & 96.9 & $45(40.9-49.0)$ & $160(134.1-185.8)$ \\
\hline Total & 611 & 96.7 & $45(4 I .4-48.6)$ & $140(|17|-.\mid 62.8)$ \\
\hline
\end{tabular}

Note: Time spent by people managing chronic obstructive pulmonary disease indicates biographical disruption.

Abbreviations: $\mathrm{N}$, number; $\mathrm{Cl}$, confidence interval.

Table S3 Time spent on nonclinical activities and self-reported health

\begin{tabular}{|c|c|c|c|c|}
\hline \multirow[t]{3}{*}{ Self-reported health } & \multirow[t]{3}{*}{$\mathbf{N}$} & \multirow{3}{*}{$\begin{array}{l}\text { Percent with nonclinical time } \\
\text { greater than zero } \\
\%\end{array}$} & \multirow{2}{*}{\multicolumn{2}{|c|}{$\begin{array}{l}\text { Nonclinical but health-related activities } \\
\text { (hours per month) } \\
\text { Median and percentile including zero } \\
\text { values }\end{array}$}} \\
\hline & & & & \\
\hline & & & Median (95\% Cl) & 90th percentile \\
\hline Excellent/very good & 30 & 88.8 & $1.5(0.3-2.7)$ & $15(4.5-25.5)$ \\
\hline Good & 115 & 87.4 & $1.5(0.6-2.4)$ & $16.2(3.8-28.5)$ \\
\hline Poor/fair & 464 & 84.3 & $1.8(1.3-2.3)$ & I2.2 (8.9-I5.5) \\
\hline Total & 611 & 85.02 & $1.5(1.0-1.9)$ & $13(9.7-16.3)$ \\
\hline
\end{tabular}

Note: Time spent by people managing chronic obstructive pulmonary disease indicates biographical disruption.

Abbreviations: $\mathrm{N}$, number; $\mathrm{Cl}$, confidence interval. 
Table S4 Time spent on clinical activities and self-reported health

\begin{tabular}{|c|c|c|c|c|}
\hline \multirow[t]{3}{*}{ Self-reported health } & \multirow[t]{3}{*}{$\mathbf{N}$} & \multirow{3}{*}{$\begin{array}{l}\text { Percent with clinical activities } \\
\text { time greater than zero } \\
\%\end{array}$} & \multicolumn{2}{|c|}{ Clinical activities (hours per month) } \\
\hline & & & \multicolumn{2}{|c|}{ Median and percentile including zero values } \\
\hline & & & Median $(95 \% \mathrm{CI})$ & 90th percentile \\
\hline Excellent/very good & 30 & 78.6 & $2.5(0.2-4.8)$ & $13.2(0.0-27.1)$ \\
\hline Good & 115 & 87.2 & $2(1.1-2.9)$ & II (5.8-16.2) \\
\hline Poor/fair & 464 & 89.9 & $3.7(3.0-4.3)$ & $18(15.2-20.8)$ \\
\hline Total & 611 & 88.6 & $3.2(2.7-3.7)$ & $16.3(13.5-19.0)$ \\
\hline
\end{tabular}

Note: Time spent by people managing chronic obstructive pulmonary disease indicates biographical disruption.

Abbreviations: $\mathrm{N}$, number; $\mathrm{Cl}$, confidence interval.

Table S5 Time spent on home activities excluding exercise and self-reported health

\begin{tabular}{|c|c|c|c|c|}
\hline \multirow[t]{3}{*}{ Self-reported health } & \multirow[t]{3}{*}{$\mathbf{N}$} & \multirow{3}{*}{$\begin{array}{l}\text { Percent with home activities } \\
\text { time greater than zero } \\
\%\end{array}$} & \multicolumn{2}{|c|}{$\begin{array}{l}\text { Home activities excluding exercise } \\
\text { (minutes per day) }\end{array}$} \\
\hline & & & \multicolumn{2}{|c|}{ Median and percentile including zero values } \\
\hline & & & Median $(95 \% \mathrm{Cl})$ & 90th percentile $(95 \% \mathrm{Cl})$ \\
\hline Excellent/very good & 30 & 96.0 & $7(2.5-11.4)$ & $30(0.0-140.7)$ \\
\hline Good & 115 & 93.0 & $10(8.2-11.8)$ & $45(27.5-62.5)$ \\
\hline Poor/fair & 464 & 96.2 & $20(16.4-23.6)$ & $90(74.9-105.1)$ \\
\hline Total & 611 & 95.5 & $15(14.0-16.0)$ & $75(62.4-87.6)$ \\
\hline
\end{tabular}

Note: Time spent by people managing chronic obstructive pulmonary disease indicates biographical disruption.

Abbreviations: $\mathrm{N}$, number; $\mathrm{Cl}$, confidence interval.

\section{Publish your work in this journal}

The International Journal of COPD is an international, peer-reviewed journal of therapeutics and pharmacology focusing on concise rapid reporting of clinical studies and reviews in COPD. Special focus is given to the pathophysiological processes underlying the disease, intervention programs, patient focused education, and self management protocols.

\section{Dovepress}

This journal is indexed on PubMed Central, MedLine and CAS. The manuscript management system is completely online and includes a very quick and fair peer-review system, which is all easy to use. Visit $\mathrm{http}: / / \mathrm{www}$. dovepress.com/testimonials.php to read real quotes from published authors. 